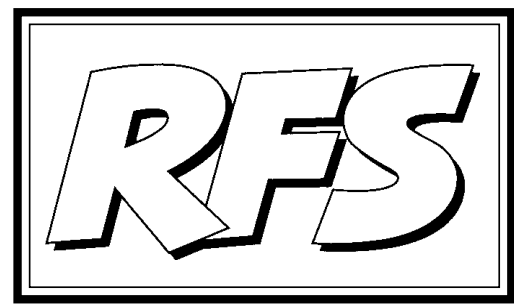

Revista de Fomento Social, 54 (1999), 343-364

\title{
El proceso de globalización de la economía mundial. Una mirada latinoamericana
}

La globalización y la década de los 90 parecen consustanciales. Es imposible en nuestros días realizar un análisis o tomar una decisión en el campo de la economía, no ya internacional, sino estrictamente doméstica, sin considerar las implicaciones que provoca la globalización en elfenómeno sujeto a estudio. Al caracterizar esta situación el autor afirma "tal pareciera que los estados del sur fueran los perdedores del proceso y los del norte, como siempre, los que obtienen las máximas ventajas del actual diseño mundial".

En un apretado resumen el articulista nos ofrece, desde la óptica de un latinoamericano, un análisis del concepto de globalización, su relación con los objetivos más generales de la política económica, la valoración de las implicaciones de la globalización para las economías menos desarrolladas y las posibles formas de regulación de la nueva economía mundial.Por su nacionalidad cubana, no podían faltar algunas reflexiones sobre la inserción de la atípica economía del país caribeño en el mundo globalizado que le ha tocado vivir.

\section{Alejandro DURÁN CÁRDENAS(*)}

(*) Profesor de Política Económica de la Facultad de Economía de la Universidad de la 


\section{Introducción. Antecedentes del proceso de globalización}

La globalización y la década de los 90 parecen consustanciales. Es imposible en nuestros días realizar un análisis o tomar una decisión en el campo de la economía no ya internacional, sino estrictamente doméstica, sin considerar las implicaciones que provoca la globalización en el fenómeno sujeto a estudio.

Es el ámbito de la Política Económica donde, tal vez, se sientan con mayor peso las implicaciones del nuevo mundo global; los diseñadores de políticas y los gobernantes encargados de aplicarlas tienen ante sí el reto de un mundo que impone reglas y nuevos comportamientos hacia lo interno de los países.

Por otra parte, la globalización (1) de la economía en la presente década puede interpretarse como un estadio superior de un proceso continuo que, para fijarle un comienzo, está en germen desde la descomposición de la comunidad primitiva y se potencia con el inicio del capitalismo como sistema económico. La vocación internacional del capital no es más que una respuesta al reto que impone el desarrollo en cantidad y calidad de nuevos productos, técnicas y tecnologías. Es evidente que el mundo global puede, de manejarse bien, traer aparejados nuevos y más sorprendentes progresos en la base material de la sociedad mundial.

Ya a fines del siglo XVII comenzó a emerger un entramado de interconexiones con la expansión del intercambio internacional y la economía mundial, proceso que se amplió en los siglos XVIII y XIX con la difusión del comercio y transcendió el ámbito económico para comenzar a convertirse en un fenómeno polifacético que abarcaría también las dimensiones política y cultural.

En el siglo XIX se sientan sólidas bases para un despegue sostenido de las interrelaciones económicas entre los diferentes países. Durante ese siglo se

Habana. Profesor Invitado de la Facultad de Ciencias Económicas y Empresariales (ETEA) de la Universidad de Córdoba. El autor agradece al Consejo de Redacción de la Revista de Fomento Social y, en particular, al profesor José J. Romero Rodríguez, sus sugerencias a una versión preliminardel presente texto.

(1) Aquí aceptaremos la palabra, aunque el término globalización es al menos un neologismo en idioma castellano, muchos defienden la acepción “mundialización” para referirse al mismo fenómeno. Puede serque este término provenga más que de la castellanización del vocabloinglés "globalization", del concepto de producto global y comunicación global tan usados en los años 80. Véase el artículo «El camino de la globalización» de Agnes Bertrand, aparecido en versión electrónica en la dirección http://www. ECOROPA.org 
desarrollan en lo teórico aportes a la teoría económica más relevantes que los que dejó J.M. Keynes en nuestro siglo, y en lo material se crean enlaces de comunicación mundialqueluegohan sidoperfeccionados hasta llegar a la autopista de la información hoy en construcción. De forma resumida repasaremos sólo algunos de los momentos claves del mencionado siglo.

1776 (2) y 1815. Adam Smith publica "La Riqueza de las Naciones" (3) y David Ricardo "Principios de Economía" (4), las dos grandes obras que sustentarían la teoría del capitalismo y del comercio internacional.

1820. Fin de las guerras napoleónicas. El mundo encuentra una relativa paz, y el comercio internacional se convierte en determinante para el crecimiento económico de los diferentes países y marca una interrelación que será, desde ese momento, cada vez más creciente.

1850. Se instalan cables transoceánicos para la transmisión telegráfica, conectando a todos los continentes y aumentando en cientos de veces la velocidad de transmisión de la información comercial y económica.

1870. Se adopta el patrón oro, con lo que surgen las monedas convertibles y se facilita el pago de las transacciones internacionales.

Siglo XX. La historia posterior es conocida, con factores que han atentado a corto plazo contra el proceso (guerras mundiales, crisis de 1929, crisis del petróleo), y otros (revolución informática, mejora de medios de transporte, fin de laguerra fría) que han fortalecido la mundialización oglobalización de la economía.

Así, se arriba a la década de los 90 con un proceso que en su evolución ha creado mercados globales, con características nuevas tales como la división de la cadena de valor, es decir la intervención de más de un país en la fabricación de un bien final, lo que enlaza a los diferentes países en relaciones de complementariedad.

Por su parte los mercados financieros se han integrado en un gran mercado global fusionado, motivado por las magnitudes y el ritmo del intercambio comercial internacional de bienes y servicios y propiciado por la revolución informática en las comunicaciones; mercados mundiales, virtuales y en tiempo real son algunos

(2)La obra de Smith aunque publicada en el siglo XVIII pertenece, al menos por su influencia, a la cultura decimonónica.

(3) Como es sabido, el título completo en inglés es "An Inquiry into the Nature and Causes of the Wealth of Nations"

(4) Título completo "Principios de Economía Política y de Tributación" 
de los calificativos del actual entorno financiero mundial. La parte negativa del proceso le corresponde a la alta especulación y a la aparición de capitales extremadamente volátiles que hacen vulnerables las economías nacionales. La desconexión del movimiento financiero de la economía real es un hecho preocupante, y potencialmente recesivo, para la economía mundial.

\section{El concepto de globalización}

Centrémonos ahora en el concepto como tal. De las muchas definiciones revisadas se han escogido algunas por sus peculiaridades específicas. Comencemos con la perteneciente al sociólogo y economista brasileño Oliver Dollfus, por destacar aspectos a veces olvidados en otras definiciones.

“...El concepto de globalización está ligado a la idea de una humanidad que por primera vez funciona como un todo, como un sistema único, como un Sistema-Mundo cuya matriz y motor es el capitalismo. La globalización es esa tendencia a la construcción de un metasistema geográfico, en el cual los estados en sus territorios y las sociedades humanas desdoblan geográficamente sus culturas, sus empresas y sus mercados. El Sistema Mundo es construido por la articulación y el recubrimiento de espacios con contornos y contenidos diferentes, cada uno de los cuales forma un subsistema con sus propias libertades, con carácter local y singular, de manera que su comportamiento no es lineal ni determinista, lo que hace prácticamente imposible que las regulaciones generales del metasistema permitan pronosticar su funcionamiento en todas las escalas...”

En esta definición, poco frecuente, se refuerzan dos aspectos de laglobalización, a saber: su carácter capitalista y su concepción sistémica.

Este último aspecto merece especial atención pues nos habla de un nuevo sistema mundial no socioeconómico, sinofísico-geográfico con una integración planetaria según la organización interna y las relaciones funcionales de un metasistema mundial. Es decir que, según el autor, asistimos a un cambio de cualidad dialéctico de proporciones incalculables y afectaciones totales a todas las variables económicas, políticas y culturales de cada país singular.

Por su parte José Luis Ramírez Huízar, profesor mexicano, en su ponencia 
presentada en elForo: "Los grandes retos de México en la era de la globalización", organizado por la Revista Economía Política, en Zacatecas, México, 1996, nos ofrece su concepto de globalización de la siguiente forma:

“...El vocablo globalización intenta sintetizar las tendencias recientes del desarrollo capitalista mundial. Tales tendencias pueden resumirse en:

a) La emergencia de una gran transformación generada por la llamada tercera revolución tecnológica e industrial, impulsada, a su vez, por la electrónica, la informática, la automatización, el uso de nuevos materiales y la biotecnología en los procesos productivos.

b) Un nuevo esquema de producción global que integra en un gran número de países, vía la descentralización, toda una serie de procesos tales como la producción de partes, componentes y servicios en un ámbito que ahora tiene por sede lo que se ha dado a llamar la «gran fábrica mundial».

c) La acelerada integración de las economías nacionales a la nueva dinámica de los mercados globales, fenómeno impulsado fundamentalmente por medio de la apertura comercial y la eliminación de barreras.

d) Laformación de tres grandes bloques regionales en Europa, América del Norte y Asia, cada uno de los cuales está siendo liderado por los tres más poderosos países del mundo: Alemania, Estados Unidos y Japón.

e) La formación de alianzas económicas estratégicas entre países y entre empresas, a partir del aprovechamiento de las ventajas comparativas y la complementación productiva.

f) La crisis de las ideologías y de los esquemas teóricos que antes se presentaban como alternativas para resolver las consecuencias negativas del desarrollo capitalista, tendencia manifiesta en la desmedida propaganda que trata de imponer al neoliberalismo como la única corriente de pensamiento capaz de explicar los fenómenos de la globalización en curso. Bajo estas tendencias, en el último lustro del siglo XX el capitalismo se presenta, cuando menos hasta ahora y después de la debacle de la Unión Soviética y el mundo socialista, como la única alternativa de sistema de organización económica y social en el ámbito internacional". 


\section{Efectos de la globalización en los países del Sur}

No obstante lo completa que resulta la anterior definición, es necesario para una total conceptualización del termino analizar sus efectos en los diferentes países, tal pareciera que los estados del surfueran los perdedores del proceso y los del norte como siempre los que obtienen las máximas ventajas del actual diseño mundial.

A este respecto el "Informe sobre el desarrollo humano de 1997" elaborado por el Programa de las Naciones Unidas para el Desarrollo, hace un pormenorizado análisis (5) del que se pueden destacar los siguientes aspectos:

- Lainversión directa extranjera(IDE) se ha dirigido al mundo desarrollado en alrededor del $90 \%$ de su volumen total, del 10\% restante la mayoría del capital se ha concentrado en China.

- Según la fuente citada, la liberalización de los mercados debe aportar al cierre del periodo 1995-2001 ganancias por algo más de 212 mil millones de dólares a los países más desarrollados. En esa misma etapa se espera que, producto de la propia liberalización, los países más pobres pierdan alrededor de 3,6 miles de millones.

- El dominio de las empresas transnacionales se puede apreciar en la tabla 1.

TABLA 1

Comparación entre el volumen de ventas y el PIB de empresas transnacionales y países seleccionados (MMM de dólares, 1996)

\begin{tabular}{|cccc|}
\hline $\begin{array}{c}\text { Empresa } \\
\text { Transnacional }\end{array}$ & $\begin{array}{c}\text { Volumen } \\
\text { de ventas }\end{array}$ & País & PIB \\
\hline G. Motors & 168,8 & Turquía & 149,8 \\
\hline Ford & 137,1 & Sudáfrica & 123,3 \\
\hline IBM & 68,5 & Venezuela & 59,0 \\
\hline Nestlé & 47,8 & Egipto & 43,9 \\
\hline
\end{tabular}

Fuente: PNUD, Informe de Desarrollo Humano 1977

(5) PNUD. Informe sobre desarrollo humano 1997. Capítulo 4. 
La muestra de países está formada por estados con relativa solidez económica dentro de su región geográfica; aun así, el poder económico de las empresas que se mencionan (que no abarcan todas las más grandes existentes) es mayor que el de esos estados.

En resumen parece empíricamente demostrable que los países en desarrollo llevan la peor parte de la globalización, presentan pérdidas (los más pobres entre ellos) resultantes de la liberalización de sus mercados, reciben una muy exigua parte de la IDE (descontando las zonas de desarrollo chinas), y sus economías, en muchos casos, son más pequeñas o débiles que las empresas transnacionales más representativas.

Las causas de esta desigual situación se deben, ateniéndonos al análisis del PNUD, a:

- Mala política económica nacional. (Se refiere a la política macroeconómica de los gobiernos).

- Malos términos. (Términos de intercambio, financieros, situación de la negociación y el pago de la deuda, y corrientes demográficas).

- Malas reglas. (Aumento real de proteccionismo arancelario y no arancelario en los países desarrollados en términos relativos).

Es deciresta “polarización” de laglobalización típica del capitalismo se convierte hasta ahora en uno de sus rasgos distintivos y que potencialmente puede ser explosivo para el sistema en su conjunto.

Por lo anterior consideramos que el concepto de globalización debería responder a la siguiente definición:

"Se entiende por globalización el proceso que encuentra su base material en la revolución tecnológica y en el desmembramiento de la cadena de valor de la producción, lo cual provoca fuertes relaciones de interdependencia entre los diferentes países; y que está caracterizado por:

1. la apertura comercial de las economías, eliminando tradicionales barreras proteccionistas,

2. la internacionalización de los mercados en especial los de productos y servicios y los de capital, polarizando aún más la distribución de la riqueza, $y$ 
3. la transformación de valores sociales y culturales nacionales permitiendo su acercamiento e interconexión con los del resto de la comunidad internacional avanzando hacia una cultura mundial relativamente homogénea”.

\section{Globalización y políticas económicas}

Interpretado tal y como se ha hecho el proceso que actualmente caracteriza la economía mundial, podríamos detenernos ahora en cómo afecta el mismo al cumplimiento de los grandes objetivos de la política económica, en los países de menor desarrollo:

CRECIMIENTO ECONÓMICO. Está condicionado por el crecimiento de los principales socios comerciales, por regla general países desarrollados, los cuales representan una proporción cada vez más creciente de la demanda agregada de la economía en cuestión.

EFICIENCIA. Desde el punto de vista material y microeconómico depende en ultimainstancia del acceso que el país logre a los adelantos de la ciencia y la técnica y a la transferencia de tecnologías. En este aspecto pareciera que la globalización no ha avanzado lo suficiente, aumentando la dependencia tecnológica de los países pobres.

PLENOEMPLEO.Lamentablemente la internacionalización apunta mucho más a los mercados de bienes y capital, que al mercado de trabajo; siguen existiendo múltiples barreras y restricciones sobre todo para la movilidad de mano de obra nada o poco calificada entre países ricos y países pobres. Por lo anterior, desde este punto de vista, en buena medida aún el empleo sigue dependiendo de las políticas internas que tracen los gobiernos.

ESTABILIDADDEPRECIOS. El comerciointernacionaliza lainflación y los países se ven obligados a tomar medidas restrictivas que atentan a su vez contra otros objetivos, por ejemplo el crecimiento económico.

DISTRIBUCIÓN DE LA RENTA Y LA RIOUEZA. El "goteo" de la globalización neoliberal no se produce en la medida necesaria, por el contrario se ha demostrado que la apertura de las economías de los países en vías de desarrollo ha polarizado aún más la distribución de la renta.

EOUILIBRIO DE LA BALANZA DE PAGOS. Es el sector externo por lógica el lugar donde juega de forma más determinante la globalización; para lograr 
el equilibrio o ajuste de la balanza de pagos cada vez es más necesario captar mayores flujos de IDE, y las posibilidades del manejo de tipos de cambios se hace más dependiente del entorno internacional

La estabilidad financiera y el equilibrio de los déficits externos se han convertido en objetivos de primera línea, que no pueden alcanzarse sin un claro compromiso de disciplina fiscal, el fortalecimiento del ahorro interno, la solidez y competitividad del país y su sistema financiero, y a tono con el mundo actual, perseverancia en la aplicación de políticas que refuercen el papel de los mercados, al menos en su relación con el exterior.

Veamos el comportamiento de América Latina en la presente década:

\section{GRÁFICO 1}

Evolución de la inflación y el tipo de cambio real en América Latina

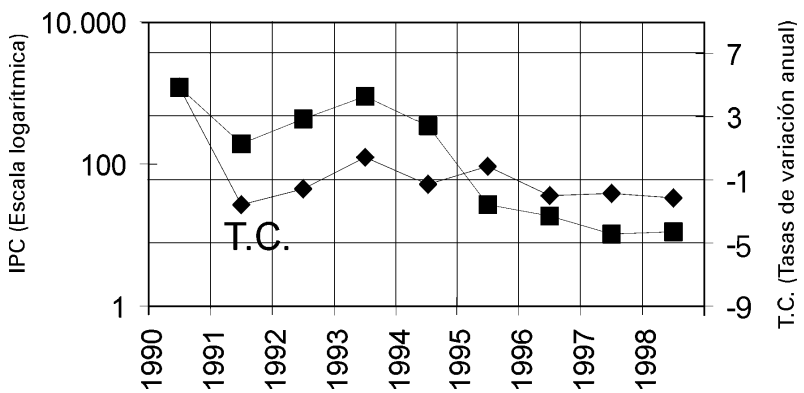

GRÁFICO 2

América Latina. Evolución del Déficit Fiscal

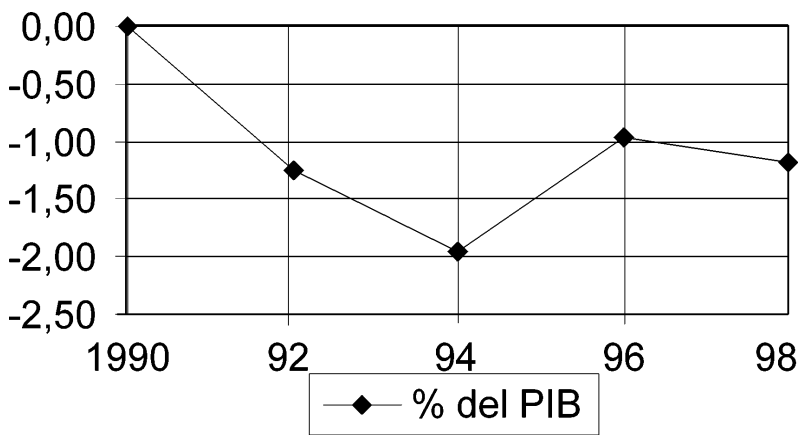




\section{GRÁFICO 1}

América Latina. Brecha comercial

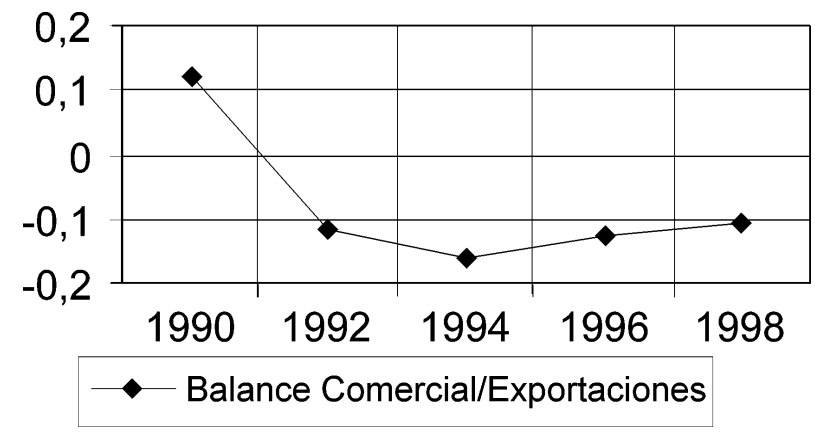

Los gráficos ponen de manifiesto la tendencia de la política macroeconómica de la región hacia la estabilización; según afirmación de CEPAL (6) comprobada por el autor, esta tendencia resultante es producto de una mayor convergencia de las políticas individuales de los diferentes países de la región.

Al menos para América Latina, aunque parece una constante mundial, la globalización en lo referente al sector externo ha aportado dos condicionantes básicas:

I. En la actualidad es imposible actuar de forma independiente al manejar la política económica, nuestras decisiones estarán siempre influidas, y en muchos casos condicionadas, por las tendencias prevalecientes en la economía mundial y, en particular, en la de aquellos países con que mantenemos mayor intercambio comercial o financiero.

II. Toda economía ha de observar una estricta disciplina macroeconómica, con el fin de disminuir en todo lo posible las divergencias en sus principales variables económicas (precios, tipos de interés, régimen fiscal, etc.) con respecto a los países de su entorno económico. La ausencia de acercamiento de las políticas macros podría traer aparejadas pérdidas de competitividad relativa, producir frecuentes oscilaciones en su tipo de cambio, constantes problemas de balanza de pagos y provocar que los resultados del país se aparten de los previstos al trazar la política económica.

Analicemos la necesaria captación de inversión directa extranjera para el área

(6) Comisión Económica para América Latina, organización del sistema de Naciones Unidas. 
y su relación tendencial con el proceso de privatizaciones; sin hacer un análisis de correlación, es evidente el fuerte condicionamiento estadístico de ambas variables según se puede apreciar en el gráfico 4.

\section{GRÁFICO 4 \\ Tendencia de la Inversión Extranjera y el monto de las privatizaciones} (millones de dólares)

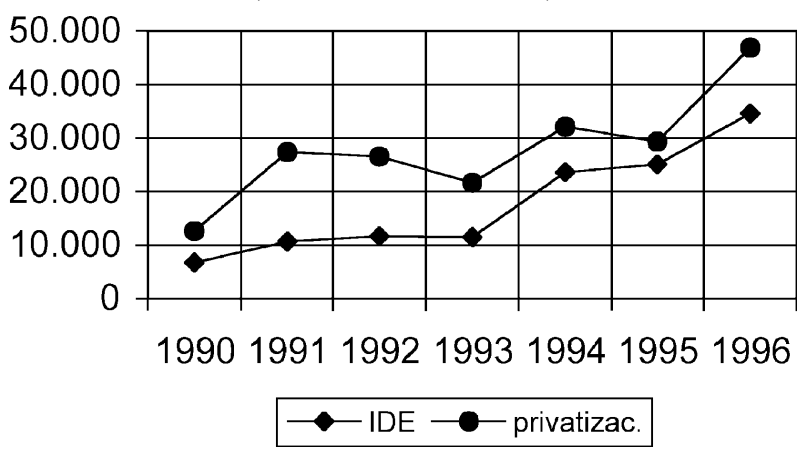

Fuente: Elaborado a partir de datos de la CEPAL.- "Estudio económico de América Latina y el Caribe 1997”.

Es obvio que, según las concepciones y práctica neoliberal vigentes, el capital acudirá a las economías con mayor grado de desregulación y mayor estabilidad macroeconómica; los efectos de esta tendencia son diferentes según los países y el cuerpo total de las políticas locales pero, como se ha venido señalando a lo largo del trabajo, todo indica que, a mayor grado de pobreza y fragilidad económica, toca menos de los efectos positivos del proceso de globalización, aumentándose la trasferencia de los países más pobres a las economías más poderosas.

En resumen, la obligada apertura al exterior de la economía, dada la globalización, condiciona los criterios del diseño de políticas y del análisis económico, de modo que, junto al comportamiento interno de la economía, debemos atender con igual énfasis a las diferencias existentes entre las variables macroeconómicas internas y las correspondientes a los países con los cuales mantenemos el mayor intercambio de bienes, servicios y capitales. A la vez, como este intercambio se amplía geográficamente, producto de la aguda internacionalización de la producción y el capital, asistiremos a una cada vez mayor globalización de la política 
económica nacional, entendida como su obligada interdependencia con las del resto del mundo.

\section{Respuestas al proceso de globalización}

El desbordamiento de los mercados de sus límites nacionales y la alta movilidad de los capitales ha sido un fenómeno que hasta ahora no ha encontrado una respuestaen formas de adaptación o regulación internacional que intente potenciar sus efectos positivos minimizando sus consecuencias adversas. Tal vez, después de la crisis asiática, ha sido cuando más evidente ha resultadola necesidad de ciertas normas que regulen el proceso de globalización.

La primera respuesta adaptativa a las nuevas condiciones del entorno mundial fue sin duda la regionalización económica. A medida que avanza el proceso de construcción de una economía mundial globalizada e interdependiente se produce a su vez un proceso de regionalización, agrupándose el mundo en grandes bloques económicos a los cuales o pertenecen, o tienen fuertes vínculos con los mismos, la casi totalidad de los países.

El regionalismo puede entenderse como el proceso mediante el cual los diferentes países conducen la integración económica, sin renunciar a su autonomía política, para tener una mejor posición de incidencia en los flujos de comercio e inversión. Es decir la regionalización (7) es una consecuencia adaptativa a la globalización. Esta se caracteriza por la formación de grandes espacioseconómicos donde están presentes las grandes economías industrializadas de conjunto con países de menor desarrollo relativo o en vías de desarrollo. Los flujos comerciales, ante la existencia de la regionalización, pueden dividirse en interregionales e intrarregionales, ocupando estos últimos un alto peso en la conformación de la estructura del comercio mundial.

El comercio intrarregional crece sin excepción, en 1996 con respecto a 1975, siendo marcado el carácter "cerrado" de la Unión Europea que absorbe ella misma más del $60 \%$ de sus flujos comerciales.

Sin embargo, en el casode América Latina no sucede así; los flujos intrarregionales

(7) Hablamos del actual regionalismo (nuevo regionalismo, según Naciones Unidas); esta tendencia presente desde la posguerra ha tenido varios momentos, pero el actual es, por sus especifidades, de una cualidad nueva. 
son relativamentemás bajosqueen otros procesos de regionalización, sibienmuestran una tendencia ascendente, veámoslo más detenidamente de forma gráfica en los gráficos 5 y 6 . Al analizar los mismos es de destacar la mayorcoherencia relativa del MERCOSUR con respecto a otros acuerdos subregionales, el cual para 1996 había superado la barrera del $20 \%$ en cuanto a su comercio interno. Es evidente la poca integración del comercio intrarregional dentro del acuerdo de la CARICOM que la convierten en el área de menor desarrollo, según este indicador.

\section{GRÁFICO 5}

Exportaciones totales y intrarregionales (millones de dólares)

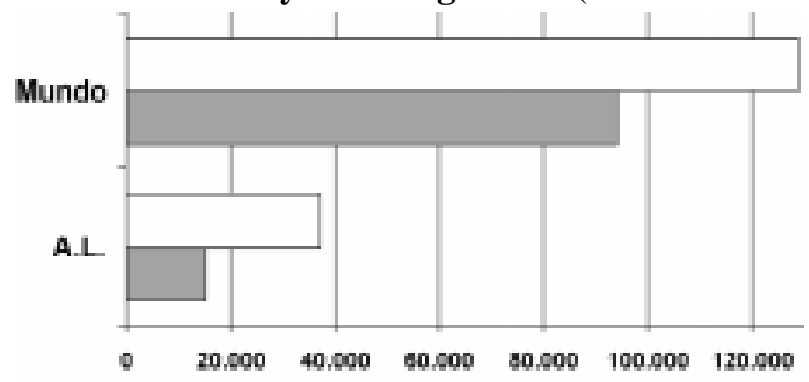

\section{$1990 \square 1995$}

GRÁFICO 6

Exportaciones dentro del grupo, de grupos subrregionales seleccionados (miles de millones de dólares)

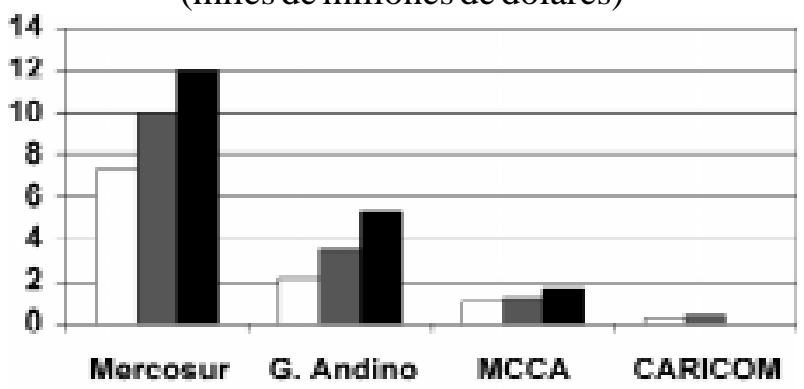

\section{$1992=1994 \mathbf{E} 1996$}

Fuente: CEPAL.- Panorama de la internacional de América Latina y el Caribe, 1996 y CEPAL. - Estudio económico de América Latina y el Caribe 1996/97, 1997. 
Dentro de la regionalización existen diversas figuras que representan niveles más profundos o no de integración de la economía; van desde el proceso integracionista más fuerte en la actualidad, la Unión Europea, de hecho ya una unión monetaria, pasando por zonas de libre comercio (Tratado de Libre Comercio), mercado común (Mercosur), o acuerdos en diferentes fases de perfeccionamiento de la unión aduanera.

Globalización y regionalización pueden ser procesos complementarios si se ve la regionalización como una forma de dividir al mundo en menos fragmentos para hacermás fácil los flujos de mercancías y capitales, o si se analiza la regionalización como etapa hacia la construcción del mercado común mundial.

Pueden revestir un carácter si no antagónico, al menos divergente, si aumenta la protección hacia lo interno de los grupos regionales, continúa disminuyendo el comercio interregional y la relación entre bloques se hace bajo normas distintas a las del libre comercio internacional.

Esta primera respuesta adaptativa a la globalización permite a los países moverse como grupoen las negociaciones globales, por ejemplo en la Organización Mundial de Comercio (OMC), elaborar políticas comunes en materia de atracción de capital, y coordinar políticas comerciales y productivas. Además, cada país miembro de un acuerdo regional puede gozar de ventajas especiales y protección dentro de su región, que estarían vetadas si actuara como un país independiente, dadas las normas vigentes del comercio internacional, aprobadas por la OMC (8). No menos ventajosa es la ampliación de su mercado interno a toda la región y las posibilidades de movilizar ahorro de otros países de su entorno o exportar capitales en regímenes protegidos dentro de la misma.

La regionalización, allí donde normalmente existe una gran potencia que lidera el área económica, puede aumentar los peligros de la dependencia de los países menos desarrollados a esos centros de poder y aun incrementar más el intercambio ya desigual existente.

(8) Los acuerdos de la OMC excluyen preferencias arancelarias, y eliminan la mayoría de las formas de proteccionismo económico en el comercio entre países, pero prevén la existencia de acuerdos regionales con características y reglas específicas hacia lo interno. 


\section{Regular la globalización a favor de los más débiles}

Como factor objetivo la globalización se ha impuesto con sus propias reglas y dinámicas que amenazan a los países en vías de desarrollo y puede profundizar las distancias entre primer y tercer mundo; es hora, pues, de crear los mecanismos que la regulen y adecuen a las necesidades de los más necesitados. En el ámbito internacional cada vez más economistas y políticos se encargan de demandar la creación de mecanismos de regulación supranacionales a tono con la globalización.

Centrándonos en las cumbres iberoamericanas de 1997 y 1998 en Isla Margarita y Oporto respectivamente, es interesante reseñar los planteamientos de algunas personalidades. Así por ejemplo el uruguayo Enrique Iglesias, presidente del Banco Interamericano de Desarrollo (BID), expresó que la globalización «es un hecho inesquivable» y que «abre grandes oportunidades, pero tiene grandes riesgos».

Según Iglesias, «se requiere reforzar como nunca el papel del sistema internacional de instituciones que aseguren la transparencia en las reglas del juego, que reduzcan las tentaciones especulativas y que asuman la tarea de vigilancia y supervisión que tanto necesita este mundo globalizado».

Por su parte el presidente brasileño, Fernando Henrique Cardoso, destacó «la necesidad de crear reglas claras y universales para regular el mercado» Cardoso dijo a los mandatarios de los otros 20 países que integran la Comunidad Iberoamericana (entre ellos España y Portugal) que tienen «como sujetos activos de los estados que representamos, la responsabilidad de condicionar el mercado a reglas del juego que no permitan que éste (el mercado) destruya las sociedades» (9).

Lo que se constata en la actualidad es que los organismos internacionales existentes, al menos con su estructura, composición, y formas de funcionamiento actuales, no están en capacidad de dirigir el proceso a fin de aprovechar los efectos benéficos y neutralizar los negativos de ese fenómeno inevitable que es la globalización de los mercados financieros, la economía, las comunicaciones y las relaciones económicas internacionales en general.

(9)Las anteriores citas han sido tomadas del trabajo "España, Portugal y América Latina: Hay que regular la globalización" de Tito Drago aparecido en el sitio de la compañía Tips en INTERNET. 
De un análisis de los diferentes planteamientos de expertos y políticos podrían resumirse las actuales ideas sobre la regulación de la globalización en los siguientes puntos:

- Crear normas y regímenes internacionales que orienten al mercado en el sentido de disminuir las diferencias y no de aumentarlas.

- Transformar las reglas jurídicas tradicionales, que en este momento de globalización ya no son suficientes para promover un equilibrio de fuerzas y un ordenamiento justo, que promueva el crecimiento y el desarrollo económico y social.

- Reforzar las formas de cooperación mutuamente ventajosas entre los diversos espacios económicamente integrados, proyectando crecientemente sus economías en la escena internacional.

- Reformar el sistema de Naciones Unidas para que sus agencias especializadas y sus diversos órganos de debate jueguen un papel activo en la regularización de la globalización.

- Aun los defensores de la corriente económica neoliberal, que se opone a cualquier forma de regulación del movimiento de mercancías y capitales o a aumentos del peso de los estados nacionales en la vida económica, están de acuerdo en aumentar el poder de las instituciones establecidas, como el FMI, el Banco Mundial y el BID, para corregir algunas imperfecciones del liberalismo económico en el ámbito global.

Recapitulando vemos cómo la globalización impone a los países del mundoen vías de desarrollo dos necesidades básicas, la primera integrarse en su área geográfica o de mayor flujo comercial y la segunda, luchar por lograr mecanismos que regulen supranacionalmente el proceso de globalización para corregir los elementos nocivos del mismo.

Dicho de otra forma, en el actual contex to mundial resulta cada vez más difícil enfrentarse individualmente al mercado internacional de mercancías y capitales, y es un imperativo el cambio de las reglas de juego neoliberales de la globalización a partir de su regulación a favor de las naciones de menor desarrollo. Si bien la regionalización es en sí ya un hecho, habría que analizar el papel de cada país en los diferentes bloques regionales y la dirección de los flujos de excedentes.

En cuanto a la regularización resulta incompatible con la tendencia neoliberal vigente en la actualidad que reclama e impone exactamente lo contrario; lo anterior condiciona no sólo el accionar práctico de las naciones menos desarrolladas sino 
la investigación teórica que pueda justificar modelos alternativos viables.

\section{Cuba en el ámbito de un mundo globalizado}

La reinserción cubana en la economía mundial es un proceso complejo y no se puede analizar al margen de la política del gobierno norteamericano que trata precisamente de aislar internacionalmente a este pequeño país, que presenta una economía deprimida y desde el fin de la guerra fría, sin importancia estratégica.

Parece demostrado que las respuestas adaptativas a la globalización son en lo externo, entre otras, la integración económica en acuerdos regionales o subregionales, y la armonización de las políticas económicas con los países con los que se mantiene el mayor intercambio comercial, y en lo interno la eliminación gradual de las barreras proteccionistas y la apertura a la entrada de capital, preferentemente en forma de IDE.

En el anterior contexto Cuba ha dado pasos de avances; así hay tres hechos claves en lo que se refiere a la integración o al menos al acercamiento a grupos regionales:

- La inclusión del país como observador en la IV convención de Lomé y su muy probable entrada al acuerdo resultante del post-Lomé en el año 2000.

- La entrada de Cuba a la ALADI (10).

- La inclusión en la Organización de Estados del Caribe, el acercamiento a la CARICOM, y su carácter de observadora en el CARIFORUM (11).

En cuanto a la armonización de políticas, al no pertenecer a ningún acuerdo de integración es difícil encontrar patrones de comparación. No obstante el país necesita, para lograr mayor competitividad, acercar su forma de funcionamiento económico a la práctica internacional, dando más peso al mercado como regulador y más libertad a los agentes económicos.

Un análisis del intercambio comercial arroja que Cuba cuenta con un comercio diversificado donde los principales socios (España, Federación Rusa y Canadá), apenas representan el $31 \%$ del intercambio total. Por grandes áreas geográficas Europa representa el $46 \%$ de todas sus relaciones comerciales, América el 39 y

(10) Asociación Latinoamericana de Integración.

(11) CARIFORUM, formado por los países de la comunidad del Caribe (CARICOM) más RepúblicaDominicanay Haití. 
Asia el 12. En todas las Américas, al excluir los cuatro países con mayores relaciones (12) el intercambio comercial no llega al $12 \%$.

En el anterior contexto, más que acercar sus políticas e indicadores económicos a los de una área geográfica especifica, Cuba debe trabajar por lograr una economía saludable capaz de insertarse en cualquier acuerdo integracionista, en condiciones aceptables.

Ante la lectura de sus resultados económicos, es preciso tomar en consideración que la isla continúa siendo una nación con control de precios y poco espacio para el mercado, no obstante el país ha logrado, no importa el análisis que se haga, buenos resultados en datos claves (ver tabla 2).

El desempleo en lo fundamental fue eliminado de Cuba al inicio de la revolución de 1959; no obstante en la actualidad si bien es cierto que la tasa de desocupación se mantiene baja con respecto a otros países (13), no deja de ser un problema complejo de resolver en algunas regiones de Cuba. Habría que añadir además problemas de subempleo que afectan la eficiencia de la planta productiva cubana.

En cuanto a la inflación, si bien en términos del índice de precios al consumo la misma fue de $2,7 \%$ en 1998 , existen presiones inflacionistas acumuladas, en forma de excedentes monetarios en manos de sectores de la población, para los cuales no existe oferta interna.

(12) Canadá, Antillas Holandesas, México y Venezuela

(13) Según CEPAL la tasa de desempleo disminuyó de 7,6\% en 1996 a 6,9\% en 1997. Estas cifras tomadas de fuentes oficiales cubanas notienen en cuenta que las estadísticas sólo registran como desempleados a las personas que acuden a las oficinas del trabajo a solicitar empleo y se supone que éstas, por lo general, llegan a las oficinas como segunda o tercera opción, después de haber intentado la búsqueda por gestiones propias, directamente en las entidades en las que están interesados. Además la PEA en esos cálculos está en algo minorada, dado que personas que en otras condiciones demandarían trabajo deciden sumergirse en actividades ilícitas, apareciendo como parte de la población que no demanda trabajo. 
TABLA 2

Cuba: Algunos indicadores macroeconómicos

\begin{tabular}{|l|c|c|c|}
\hline Indicadores & $\mathbf{1 9 9 3}$ & $\mathbf{1 9 9 7}$ & $\mathbf{1 9 9 8}$ \\
\hline Déficit fiscal & 33 & 2,5 & 2,3 \\
\hline Tasa de incremento del PIB anual & 0,85 & 7,8 & 1,2 \\
\hline Crecimiento de la deuda (1993=100) & 100 & 116 & 129 \\
\hline Saldo cuenta corriente (MM de pesos) & $-371,6$ & $-436,7$ & $-396,3$ \\
\hline
\end{tabular}

Fuente: Cálculos del autor sobre la base del Anuario estadístico de Cuba 1996 e Informe del Banco Central de Cuba, 1998.

Sobre lainversión directa de capital extranjero, desde 1982 existe una legislación en Cuba que la permite y regula; no obstante hasta inicios de la crisis no se elabora todo un plan que tiende a incrementar el número y la cantidad de capitales invertidos. Así se establece un atrayente régimen fiscal, se permite la repatriación del $100 \%$ de los beneficios, se contempla la posibilidad de inversiones totalmente extranjeras y se crean zonas francas industriales y comerciales. Esta política que ha atraído a un determinado número de capitales, aún es insuficiente para los niveles necesarios que necesita la economía. Los sectores más beneficiados con la IDE son, entre otros, el turismo y la actividad extractiva de metales no ferrosos y petróleo, también existen algunas inversiones de alguna consideración en telefonía.

Aunque el número de inversionistas continúa creciendo a partir de 1994, a pesar de la presión en contra ejercida por el gobierno norteamericano, el volumen total de la inversión disminuye significativamente precisamente después de dicho año.

La posibilidad de integración y de reinserción de Cuba en el mundo globalizado está más que probada. Su situación económica, aunque compleja no es peor que la de otros muchos países beneficiados con acuerdos regionales o subregionales. Es necesario, pues, entre otros aspectos:

- Que el país adapte aún más su forma de funcionamiento económico a las del resto del mundo.

- Que mejore su eficiencia interna y la competitividad internacional de sus importaciones tradicionales y no tradicionales.

- Que paulatinamente ganen peso en su intercambio comercial aquellos países 
más probables con vistas a una integración económica.

- Que se levante el bloqueo norteamericano contra el país.

En la visita de Su Santidad el Papa a Cuba el pasado año se exhortaba a que Cuba se abriera al Mundo. Esta apertura, obligada y necesaria, deberá pasar por un estudio profundo del proceso de globalización identificando sus oportunidades y convirtiendo en ventajas las amenazas que el mismo presenta para países con niveles de desarrollo como el cubano. 


\section{Bibliografía consultada}

Banco Central de Cuba (1997), Informe 1996.

Banco Mundial (1997), World Development Report 1997.

Banco Mundial (1996), Informe sobre el desarrollo mundial 1996.

BERTRAND, A. (1998), El camino de la globalización. Versión electrónica en la dirección <http://www.ECOROPA.org>.

Centro de Estudios de la Economía Cubana (1997), Informe 1996.

CEPAL (1998), Estudio económico de América Latina y el Caribe 1996-1997.

CEPAL (1996), Panorama de la inserción internacional de América Latina y el Caribe.

Cuadrado Roura, J.R.; Mancha Villena, T.; Casares, J.E.; González, M.J. (1997), Introducción a la Política Económica. Ed. Mc Graw-Hill.

De Sousa Santos, B. (1995), Toward a new common sense. New York, London, Routledge.

Delgado, O. (1996), «La perspectiva geográfica de la globalización». Trimestre Geográfico, No.16.

Dollfus, O. (1998), «Geopolítica do sistema-mundo. O novo mapa do mundo, fim de século e globalizacao». Sao Paulo, Editora HUCITEC, INTERNET, Sitio de la Compañía Tips.

Dornbusch, R. y Fischer, S. (1994), Macroeconomía. Ed. McGraw-Hill.

Drago, T. (1998), «España, Portugal y América Latina: Hay que regular la globalización». Sitio de la compañía Tips en INTERNET.

DuRÁN, A. (1998), «Una respuesta no ortodoxa, la crisis y la recuperación cubana», Revista de Fomento Social, n 210, abril-junio, pp. 203-222.

Neme, J. y C. (1979), Políticas Económicas Comparadas. Editorial VicensVives.

Oficina Nacional de Estadísticas (1996), Anuario económico de Cuba, 1996.

Peter, Jc. (1993), Political geography of the twentieth century: A global analysis. London, Belhaven Press.

PNUD (1997), Informe sobre desarrollo humano 1997. Mundi-Prensa Libros S.A. Madrid, España.

RAmírez HuízAR, J.L. (1998), Ponencia presentada en el Foro: «Los grandes retos de México en la era de la globalización», Zacatecas, México». Tomado de INTERNET, Sitio de la compañía Tips. 
RodrígueZ, J.L. (1997), «Informe sobre los resultados económicos de 1997 y el plan económico y social para 1998». Periódico Trabajadores, La Habana, 1512-1997

TrianA, J. (1999), «Cuba: Perspectiva global del desempeño macroeconómicoen 1997». (En prensa). 